\title{
Qualidade de cachaças artesanais produzidas com leveduras de diferentes origens
}

\author{
Quality of artisanal cachaças produced with yeasts of different origins \\ J. A. A. de Moura; C. M. Belisário*; L. F. Viana; M. P. da Silva Filho; B. A. de \\ Moura \\ Programa de Pós-Graduação em Tecnologia de Alimentos, Instituto Federal Goiano, 75901-970, Rio Verde-Goiás, \\ Brasil \\ *celso.belisario@ifgoiano.edu.br \\ (Recebido em 22 de novembro de 2019; aceito em 24 de março de 2020)
}

\begin{abstract}
A cachaça brasileira é produzida a partir da destilação do caldo de cana-de-açúcar fermentado, possuindo graduação alcoólica entre 38 e $48 \%$. Essa bebida possui características sensoriais peculiares, que variam de acordo com o processo produtivo. O objetivo do estudo foi produzir cachaça artesanal, com destilação em alambique de cobre, utilizando-se leveduras Saccharomyces cerevisiae comercial (Fleischmann ${ }^{\circledR}$ e Levapan $\left.{ }^{\circledR}\right)$ e selecionada (CA-11), e identificar a melhor bebida de acordo com determinados parâmetros físico-químicos e sensoriais. A graduação alcoólica média das cachaças variou entre 40,30 e 45,90\% (v/v). Os teores de acidez volátil, ésteres totais, metanol, furfural e cobre, estão em conformidade com a legislação vigente. A partir da análise sensorial, verificou-se maior aceitação para o atributo cor nas cachaças produzidas por leveduras comerciais. A cachaça produzida pela levedura Levapan ${ }^{\circledR}$ apresentou maior aceitabilidade para o atributo aroma, e a cachaça produzida por levedura CA-11 foi a mais aceita para os atributos sabor e impressão global. As cachaças produzidas apresentaram boa qualidade físico-química, com presença de voláteis e outros componentes dentro do estabelecido pela legislação vigente, e as produzidas com levedura selecionada foram mais bem avaliadas pelos provadores.

Palavras-chave: Bebida destilada, Levedura, Análise sensorial.
\end{abstract}

The Brazilian Cachaça is produced from the distillation of fermented sugarcane juice, with an alcoholic strength between 38 and $48 \%$. This drink has peculiar sensorial characteristics, which vary according to the productive process. The objective of the study was to produce artisanal cachaça, with copper distillation using commercial yeasts Saccharomyces cerevisiae (Fleischmann ${ }^{\circledR}$ and Levapan ${ }^{\circledR}$ ) and selected (CA-11), and to identify the best beverage according to certain physicochemical parameters and sensorial. The average alcohol content of the cachaças ranged from 40.30 to $45.90 \%$ (v/v). The contents of volatile acidity, total esters, methanol, furfural and copper, are in compliance with the current legislation. From the sensory analysis, it was verified a greater acceptance for color attribute in the cachaças produced by commercial yeasts. Cachaça produced by Levapan ${ }^{\circledR}$ yeast showed greater acceptability for the aroma attribute, and the cachaça produced by yeast CA-11 was the most accepted in terms of flavor and overall impression attributes. The cachaças produced showed good physical-chemical quality, with the presence of volatiles and other components within the established by current legislation, and those produced with selected yeast were better evaluated by the tasters.

Keywords: Distilled drink, Yeast, Sensory analysis.

\section{INTRODUÇÃO}

A produção, padronização, classificação, registro, inspeção e a fiscalização de bebidas, incluindo a cachaça, são feitos de acordo com o Decreto Presidencial $n^{\circ} 6871$, de 04 de junho de 2009, que regulamenta a Lei $\mathrm{n}^{\circ} 8.918$, de 14 de julho de 1994. A cachaça é um destilado produzido em diversas regiões do Brasil, constituída por uma solução de etanol, água e compostos com aromas peculiares, provocados por ésteres, aldeídos, ácidos orgânicos e álcoois superiores $[1,2]$. Como consequência da expansão de produção e consumo, esta bebida é considerada tipicamente brasileira, que consolidou seu espaço no mercado e assumiu um importantíssimo papel econômico, cultural e social [3,4], além de ser uma das bebidas alcoólicas mais consumidas internacionalmente $[5,6]$.

Para continuar a ganhar espaço na preferência dos consumidores, bem como garantir o cumprimento das exigências de qualidade dos mercados interno e externo, as tecnologias de

$$
031501-1
$$


produção de cachaça devem estar associadas aos cuidados com a instalação e aplicação de parâmetros que garantam as qualidades sensoriais, físico-químicas e microbiológicas [7].

Dentre esses parâmetros, pode se destacar o tipo de fermento utilizado, que podem ser classificados em: fermento natural e fermento selecionado. O primeiro é comumente usado na produção artesanal de cachaça, e por possuir uma gama de espécies de leveduras dificulta a padronização da produção. Já a utilização de fermento selecionado, viabiliza maior reprodutibilidade, uma vez que é composto por leveduras de uma única espécie, resultando em características favoráveis à velocidade de fermentação, redução de contaminantes e qualidade sensorial $[8,9]$.

Durante o processo de produção da cachaça, pode haver a formação de diversos compostos voláteis que influenciam diretamente na qualidade sensorial do produto: ácidos orgânicos, metanol, ésteres, aldeídos e álcoois superiores. No entanto, muitos desses compostos apresentam elevada toxicidade, o que demanda o uso de boas práticas de fabricação e métodos $[8,9,10]$, que possam evitar que suas concentrações ultrapassem os limites estabelecidos pela legislação [11].

Outro fator que influencia na qualidade da cachaça é o tipo de alambique. Dentre os comumente utilizados, há evidente preferência quanto ao uso do alambique de cobre, que pode auxiliar na eliminação de alguns aromas desagradáveis. No entanto, cuidados com a limpeza devem ser tomados para diminuir a presença deste metal na bebida, que de acordo com a legislação, a concentração máxima deve ser de $5 \mathrm{mg} \mathrm{L}^{-1}$ no produto final [12].

Dentro desse contexto, o objetivo do estudo foi produzir cachaça artesanal, utilizando no processo de fermentação, leveduras Saccharomyces cerevisiae de diferentes origens, e identificar a melhor bebida de acordo com alguns parâmetros físico-químicos e sensoriais.

\section{MATERIAL E MÉTODOS}

Os experimentos foram conduzidos de abril a agosto de 2017, no Instituto Federal Goiano, Campus Rio Verde, em Rio Verde, GO, Brasil. Utilizaram-se canas-de-açúcar da variedade RB 855453 , fornecidas por um pequeno produtor da região. As canas foram cortadas, higienizadas e transportadas para a extração do caldo em moenda elétrica, previamente higienizada. O teor de sólidos solúveis inicial das amostras, em torno de $20^{\circ}$ Brix, foi padronizado com adição de frações de água destilada, para $16 \pm 1,5^{\circ}$ Brix.

As dornas foram preparadas com baldes plásticos de capacidade $15 \mathrm{~L}$, previamente higienizados. Em cada balde foram adicionados $7 \mathrm{~L}$ de caldo, divididos em três tratamentos, em triplicata. Os tratamentos foram: tratamento 1: fermento biológico seco, marca Fleischmann®; tratamento 2: fermento biológico fresco, marca Levapan ${ }^{\circledR}$ e tratamento 3: fermento selecionado CA-11, marca LNF Latino Americana Consultoria Assessoria e Importação Ltda. As massas de levedura para os tratamentos 1 e 2 , foram equivalentes a $20 \mathrm{~g} \mathrm{~L}^{-1}$ e para o tratamento 3 seguiu-se a recomendação do fabricante, $1 \mathrm{~g} \mathrm{~L}^{-1}$.

As fermentações foram conduzidas simultaneamente em Incubadoras B.O.D. (TE-371- Tecnal®, Brasil) com temperatura controlada em $32 \pm 2{ }^{\circ} \mathrm{C}$.

As medidas de sólidos solúveis foram realizadas com refratômetro digital (DR301-95- KRÜSS, Germany), de hora em hora até a quarta hora, e a partir desse período, de duas em duas horas até o final da fermentação, definido quando o teor de sólidos solúveis se apresentou constante por duas medidas consecutivas. Após a fermentação, o vinho foi armazenado em Incubadoras B.O.D. a $4 \pm$ $0,5^{\circ} \mathrm{C}$ até o momento da destilação.

Antes da destilação determinou-se o teor alcoólico do vinho, a partir da metodologia de grau alcoólico real [13]. Foram realizados cálculos a partir do grau alcoólico do vinho para determinar a coleta do destilado denominado "coração", que é a fração com teor alcoólico entre $50 \%$ e $38 \%$ $(\mathrm{v} / \mathrm{v})$. As destilações foram realizadas em alambique de cobre de $15 \mathrm{~L}$ de capacidade. Antes da realização das destilações e entre uma destilação e outra, o alambique foi devidamente higienizado com água, sabão e uma solução de $6 \mathrm{~L}$ de suco de limão e $0,5 \mathrm{~kg}$ de cloreto de sódio.

As análises de acidez volátil, ésteres totais, metanol, furfural e cobre, foram realizadas de acordo com o Manual de Métodos Operacional de Bebidas e Vinagres [13]. 
A análise sensorial das cachaças foi realizada após o período de descanso de 3 meses e aprovação prévia do comitê de ética em pesquisa do Instituto Federal Goiano (Parecer $\mathrm{n}^{\circ}$ 2.156.696 de 03/08/2018). Os procedimentos para a realização da análise sensorial foram feitos de acordo com Borragini e Faria (2010) [14]. Foram realizados testes de preferência em escala hedônica de 7 pontos, fixada em suas extremidades os seguintes termos: "gostei extremamente" e "desgostei extremamente", para os atributos de cor, aroma, sabor e impressão global.

Os testes foram realizados no laboratório de análises sensoriais, no setor de Engenharia de Alimentos, entre as 13:30 e 18:30 h, com 50 provadores maiores de 18 anos, apreciadores de cachaça e não treinados, que demonstraram interesse em participarem voluntariamente da pesquisa após lerem, concordarem e assinarem o Termo de Consentimento Livre e Esclarecido (TCLE).

As amostras $(10 \mathrm{~mL})$ foram servidas aos provadores em copos descartáveis transparentes, previamente codificados e cobertos com vidro de relógio até o momento do teste. Os provadores foram orientados a consumirem uma bolacha de água e sal e tomar água no intervalo entre as degustações.

O delineamento experimental foi o inteiramente casualizado, com três tratamentos (Fermento biológico seco - Fleischmann ${ }^{\circledR}$, Fermento biológico fresco - Levapan ${ }^{\circledR}$ e Fermento selecionado CA-11 - LNF Latino Americana Consultoria Assessoria e Importação Ltda.) e três repetições.

A cinética de consumo dos açúcares foi realizada por meio de regressão em Microsoft Excel $2010 \AA$, plotando-se os valores de sólidos solúveis em função do tempo de atividade de fermentação. Foram comparados os valores de R-quadrado das equações geradas nos modelos Exponencial e Polinomial de graus 2 e 3 . Os dados obtidos nas análises físico-químicas, bem como os valores da escala hedônica, foram submetidos à análise de variância e as médias submetidas ao teste de Tukey $(\mathrm{p}<0,05)$, no Sisvar 5.6○. Os histogramas de frequência dos valores da escala hedônica foram construídos a partir do Microsoft Excel $2010 \circledR$.

\section{RESULTADOS E DISCUSSÃO}

As leituras dos níveis de sólidos solúveis, feitas ao longo do processo de fermentação, permitiram a plotagem de linhas de tendência e do modelo que melhor se adequou à degradação dos açúcares pelas leveduras (Figura 1).

Seco instantâneo $\left(y=-0,0049 x^{3}+0,207 x^{2}-2,8511 x+16,995, R^{2}=0,9757\right)$

Prensado fresco $\left(y=-0,0087 x^{3}+0,3187 x^{2}-3,6402 x+17,37, R^{2}=0,9093\right)$

CA-11 $\left(y=0,0002 x^{3}+0,0024 x^{2}-0,5512 x+16,415, R^{2}=0,9895\right)$

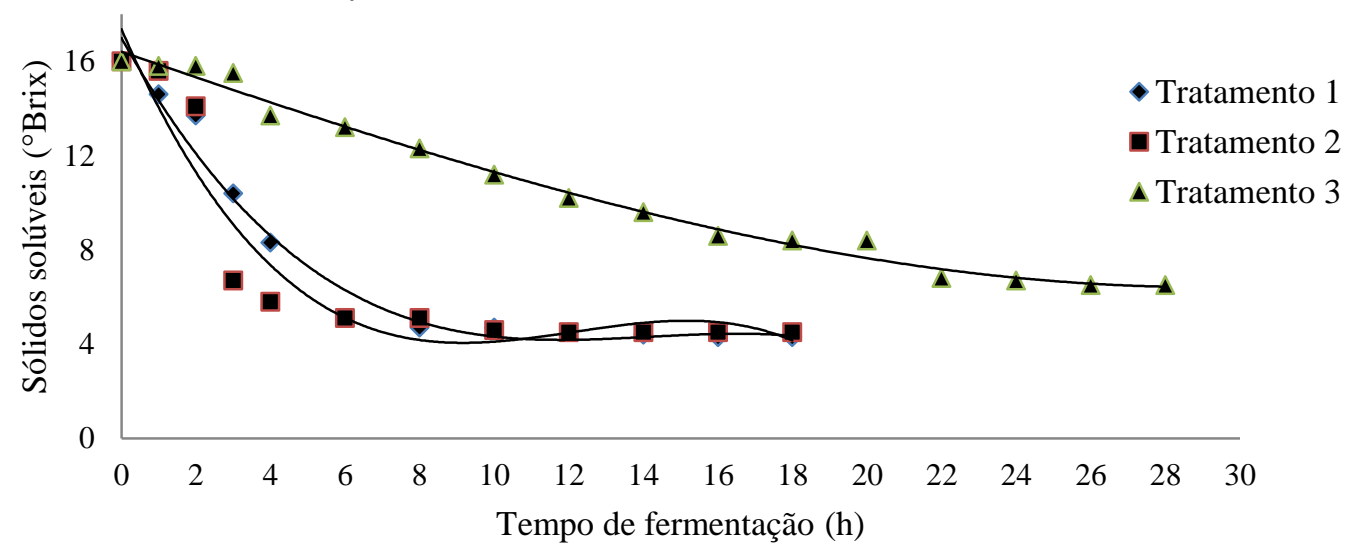

Figura 1: Linhas de tendência para o consumo de açúcares durante a fermentação com as leveduras de diferentes origens. Tratamento 1: fermento biológico seco, marca Fleischmann ${ }^{\circ} ;$ Tratamento 2: fermento biológico fresco, marca Levapan ${ }^{\circledR}$ e Tratamento 3: fermento selecionado CA-11, marca LNF Latino Americana Consultoria Assessoria e Importação Ltda.

O modelo que melhor se adequou aos dados do consumo de açúcar em função do tempo, nos três tratamentos, foi o polinomial de terceira ordem, definido por apresentar maiores coeficientes 
de determinação $\left(\mathrm{R}^{2}\right)$. Além da adequação ao modelo matemático, é importante destacar o tempo de fermentação nos tratamentos.

O tratamento 3 apresentou, após 22 horas, teor de sólidos solúveis próximo a $7{ }^{\circ} \mathrm{Brix}$, enquanto os tratamentos 1 e 2, após 10 horas de fermentação, já atingiram teores próximos a $4^{\circ}$ Brix. Portanto, os tratamentos 1 e 2, que utilizaram leveduras comerciais foram mais eficientes, pois apresentaram menores tempos de degradação dos açúcares, que de acordo com Ribeiro et. al. (2017) [9], pode reduzir os riscos de contaminação e melhorar os atributos sensoriais.

De acordo com os dados apresentados (Tabela 1), as concentrações médias de etanol presentes nas cachaças produzidas, não apresentaram diferenças entre os tratamentos, com média geral em torno de 44\% (v/v). Além do teor alcoólico, todos os resultados físico-químicos das amostras de cachaça estão de acordo com o estabelecido pela legislação vigente [11].

Tabela 1: Resultados das análises físico-químicas das cachaças produzidas com leveduras de diferentes origens.

\begin{tabular}{|c|c|c|c|c|c|}
\hline Parâmetros & Tratamento 1 & Tratamento 2 & Tratamento 3 & $\begin{array}{l}\mathrm{CV} \\
(\%)\end{array}$ & $\begin{array}{l}\text { Valores de } \\
\text { referência* }\end{array}$ \\
\hline Grau alcoólico real (\%) & $45,4 \pm 0,6 \mathrm{a}$ & $45,9 \pm 4,1 \mathrm{a}$ & $40,3 \pm 5,6 \mathrm{a}$ & 8,97 & $38-48$ \\
\hline Acidez Volátil (mg $100 \mathrm{~mL}^{-1}$ ) & $6,62 \pm 1,41 \mathrm{a}$ & $2,15 \pm 0,87 \mathrm{~b}$ & $6,05 \pm 3,07 \mathrm{a}$ & 1,16 & $<150$ \\
\hline Ésteres totais $\left(\mathrm{mg} 100 \mathrm{~mL}^{-1}\right)$ & $67,31 \pm 6,90 \mathrm{a}$ & $76,57 \pm 3,77 \mathrm{a}$ & $84,31 \pm 14,66$ a & 12,58 & $<200$ \\
\hline Metanol (mg $100 \mathrm{~mL}^{-1}$ ) & ND & ND & ND & ND & $<20$ \\
\hline Furfural (mg $100 \mathrm{~mL}^{-1}$ ) & $0,024 \pm 0,009$ a & $0,013 \pm 0,002 \mathrm{a}$ & $0,014 \pm 0,002 \mathrm{a}$ & 0,003 & $<5$ \\
\hline Cobre $\left(\mathrm{mg} \mathrm{L}^{-1}\right)$ & $2,12 \pm 0,38$ a & $1,91 \pm 0,78 \mathrm{a}$ & $2,71 \pm 0,27 \mathrm{a}$ & 0,81 & $<5$ \\
\hline
\end{tabular}

Médias na mesma linha, seguidas de letras iguais, não diferem entre si ao nível de 5\% de significância pelo teste de Tukey. Tratamento 1: fermento biológico seco, marca Fleischmann®; Tratamento 2: fermento biológico fresco, marca Levapan ${ }^{\circledR}$ e Tratamento 3: fermento selecionado CA-11, marca LNF Latino Americana Consultoria Assessoria e Importação Ltda. ND: não detectado. CV (\%): Coeficiente de variação. *Instrução Normativa nº 13, de 29 de junho de 2005, Ministério da Agricultura, Pecuária e Abastecimento.

As cachaças produzidas nos três tratamentos apresentaram teor alcoólico superior às analisadas por Amorim et al. (2016) [1], produzidas a partir de inóculo misto Meyerozyma caribbica CCMA 0198 e $S$. cerevisiae CA-11, que obteve bebidas com teor alcoólico de 40,24\% v/v e 40,88\% v/v, respectivamente.

O tratamento 2 apresentou a menor concentração de acidez volátil em ácido acético, observandose diferença significativa em relação as outras amostras. No entanto, nos três tratamentos, esses valores estão de acordo com os valores de referência estabelecidos pela legislação vigente [11]. Em estudo realizado por Fernandes et al. (2007) [12], foram analisadas 16 amostras de cachaças produzidas por cooperativas do sul de Minas Gerais, onde detectaram-se duas amostras com valores de acidez volátil superiores ao limite da legislação brasileira.

De acordo com Bortoletto e Alcarde (2015) [6], a alta concentração de acidez volátil em cachaça é proveniente da contaminação bacteriana durante o processo de fabricação. Além disso, outro fator que influencia na redução da acidez volátil na bebida é o fracionamento correto do destilado, realizando o corte ideal para a fração "cauda". A partir desse contexto, presume-se que o fracionamento e os cuidados na prevenção de contaminação durante o processo foram eficientes durante a condução dos experimentos.

Os teores de ésteres totais não apresentaram diferenças significativas entre os tratamentos e as concentrações foram inferiores ao limite máximo de $200 \mathrm{mg} \mathrm{mL}^{-1}$ [11]. Em estudo realizado por Ribeiro et al. (2017) [9], foram produzidas cachaças utilizando-se leveduras nativas e levedura CA11, com variação de caldo clarificado e não clarificado, onde obtiveram-se concentrações médias de ésteres totais dentro das conformidades da legislação, destacando-se que para os tratamentos que utilizaram a levedura CA-11, a concentração de ésteres totais foi menor que nos tratamentos realizados com leveduras nativas. 
Bogusz Junior et al. (2006) [15] realizaram análise de 27 amostras de cachaças produzidas no Noroeste do Rio Grande do Sul, onde nenhuma amostra apresentou irregularidade para a concentração de ésteres. Pode se afirmar que a qualidade das cachaças produzidas neste estudo não foi afetada pela concentração de ésteres totais, pois em todos os tratamentos, a concentração deste componente foi inferior a metade da concentração máxima admitida pela legislação [11].

A produção de ésteres pode ser relacionada com diversos fatores durante o processo de fabricação de cachaça. Estes componentes, se presentes na cachaça em altas concentrações, pode afetar de forma negativa as características sensoriais da bebida, devido à pungência característica [16]. Diferentes linhagens de leveduras podem influenciar no aparecimento dos ésteres, pois apresentam diferentes respostas metabólicas, além disso, o cobre, que é componente do alambique, é um catalisador para a produção desses compostos [10]. Algumas práticas podem reduzir a concentração de ésteres e outros voláteis no produto final. Clarificação do caldo [9], destilações consecutivas [10], e pelo uso de diferentes linhagens de leveduras [8].

Neste estudo, diferentemente de Alcarde et al. (2012) [8], a cachaça produzida com levedura selecionada CA-11, apresentou concentração de ésteres levemente maior do que a cachaça produzida com os outros tratamentos. Como os procedimentos de destilação foram feitos de forma idêntica, pode se atribuir este fato ao tempo maior de fermentação do tratamento com CA-11, favorecendo o metabolismo que resulta na produção desses compostos voláteis.

Outro composto que pode ser prejudicial, se presente na cachaça em determinada concentração, é o metanol. No entanto, não houve detecção de metanol nas amostras produzidas em nenhum dos tratamentos. Esse composto é formado a partir da pectina, que está presente no bagaço da cana. Métodos Físico-químicos, como a filtração e clarificação do caldo propostos por Ribeiro et al. (2017) [9], bem como a bidestilação e redestilação, por Silva et al. (2020) [10], podem evitar a presença dessa substância, que é um produto neurotóxico que pode ser letal.

Apesar de não terem sido realizados processos de clarificação, nem de múltiplas destilações, os procedimentos de filtragem e decantação foram eficientes na extração dos bagacilhos, resultando em produtos com concentrações de metanol abaixo do limite de detecção do método utilizado, ou provavelmente inexistente.

As concentrações médias de furfural não apresentaram diferença significativa ao nível de $5 \%$ de significância. Analisando os valores médios para este componente, observou-se que as cachaças obtidas nos três tratamentos em estudo estão de acordo com o limite máximo de $5 \mathrm{mg} \mathrm{mL}^{-1}$ definido pela legislação vigente. Em cachaças produzidas a partir de leveduras Saccharomyces cerevisiae, cepas Y-904 (AB Brasil, Pederneiras-SP, Brasil), CA-11, BG-1, PE-2, SA-1 ou CAT-1 (LNF Latino Americana, Bento Gonçalves-RS, Brasil), Alcarde et al. (2012) [8] encontraram concentrações de furfural dentro das conformidades legais, que variou de 0,30 a $0,88 \mathrm{mg} 100 \mathrm{~mL}^{-}$ 1 .

Analisando as concentrações médias de cobre, verificou-se que foram inferiores ao limite de 5 $\mathrm{mg} \mathrm{L}^{-1}$ e não diferiram estatisticamente entre os tratamentos. Existe uma relação entre a acidez e o teor de cobre na cachaça, pois o ácido acético é capaz de solubilizar o cobre que oxida na superfície do alambique [6]. Verificou-se essa relação ao comparar os valores de acidez e teor de cobre nos tratamentos 1 e 3, que apresentaram acidez volátil de 6,63 e 6,05 $\mathrm{mg} 100 \mathrm{~mL}^{-1}$, respectivamente, e teores de cobre relativamente altos com relação ao tratamento 2, que apresentou menor concentração de acidez volátil.

A ocorrência de contaminação por cobre em cachaça se dá através da higienização inadequada do alambique durante a destilação, por isso, recomenda-se a realização de uma destilação prévia com suco de limão e água para a extração do cobre oxidado na superfície do alambique [12]. Com os resultados obtidos para a concentração de cobre, pode-se afirmar que a realização da higienização do alambique com solução de ácido cítrico, cloreto de sódio e água, antes das destilações foi eficiente para a extração dos compostos oxidados na superfície do equipamento, e no controle da contaminação das cachaças produzidas.

A seguir, estão apresentados os histogramas de distribuição de frequências das respostas dos provadores para cada atributo avaliado (Figura 2). 

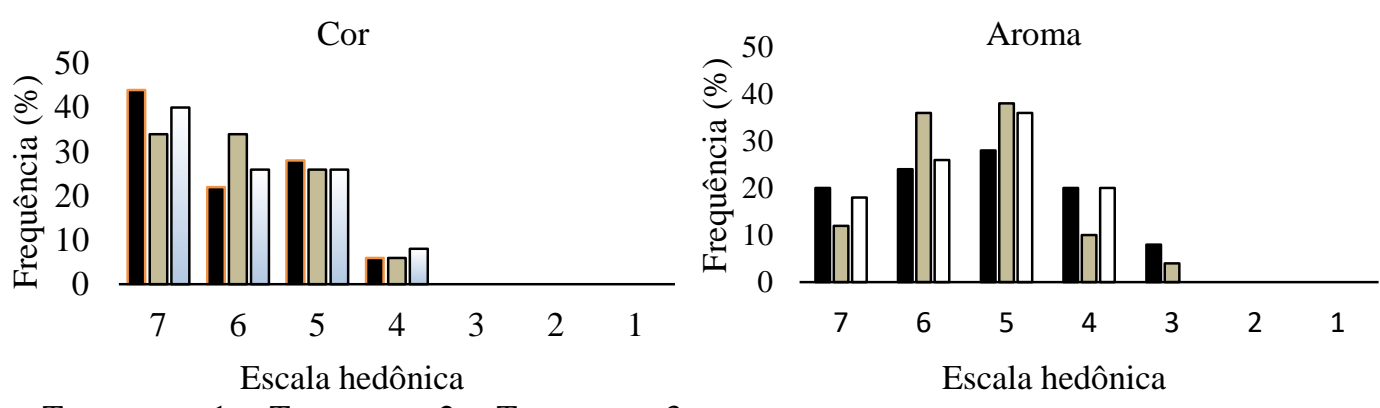

- Tratamento $1 \square$ Tratamento $2 \square$ Tratamento 3

- Tratamento $1 \square$ Tratamento $2 \square$ Tratamento 3
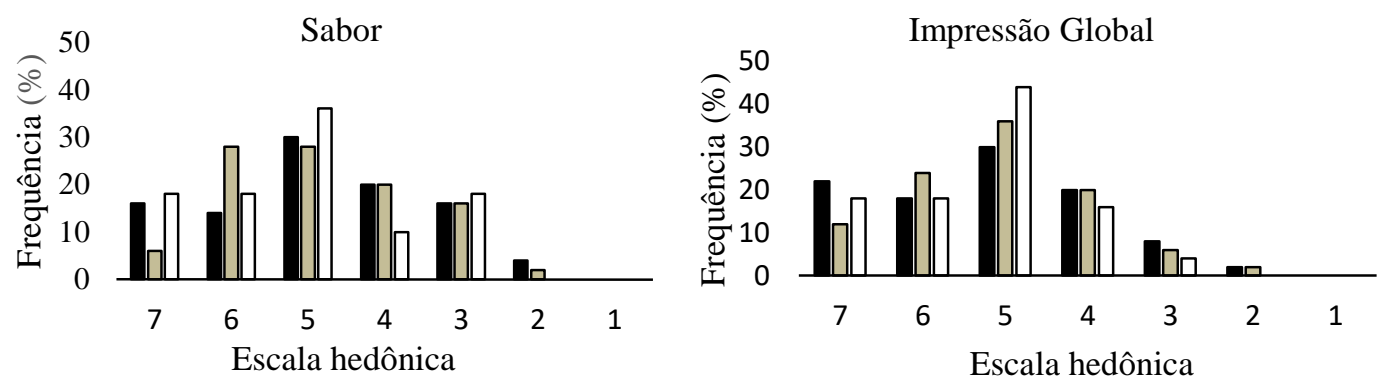

- Tratamento $1 \square$ Tratamento $2 \square$ Tratamento $3 \square$ Tratamento $1 \square$ Tratamento $2 \square$ Tratamento 3

Figura 2: Histograma de frequência dos valores hedônicos atribuídos à cor, aroma, sabor e impressão global das amostras de cachaças. (1: desgostei extremamente, 4: nem gostei, nem desgostei 7: gostei extremamente). Tratamento 1: fermento biológico seco, marca Fleischmann®; Tratamento 2: fermento biológico fresco, marca Levapan ${ }^{\circledR}$ e Tratamento 3: fermento selecionado CA-11, marca LNF Latino Americana Consultoria Assessoria e Importação Ltda.

Com relação à cor, as respostas dos provadores variaram da categoria de "nem gostei/nem desgostei" até "gostei extremamente". Os tratamentos 1 e 3 apresentaram maior frequência de aceitação na categoria 7 (gostei extremamente), enquanto o tratamento 2 apresentou maior frequência nas categorias 6 (gostei muito) e 7. Dessa forma, as cachaças produzidas a partir dos tratamentos 1 e 3 foram melhor avaliadas quanto ao atributo cor.

Quanto ao aroma, houve variação entre as categorias "desgostei" e "gostei extremamente". As cachaças produzidas a partir dos tratamentos 1 e 2 apresentaram pequena frequência de rejeição na categoria 3 (desgostei). Porém, todos os tratamentos apresentaram maiores frequências de aceitação nas categorias 5 (gostei) e 6 (gostei muito).

Para a avaliação do sabor, as respostas variaram da categoria de "desgostei muito" até "gostei extremamente". As amostras de todos os tratamentos apresentaram maiores frequências de aceitação na categoria 5, e o tratamento 2 também apresentou maior frequência na categoria 6 . Apesar das amostras dos três tratamentos apresentarem maiores frequências na categoria "gostei", as três também foram avaliadas de forma negativa na escala "desgostei" com valores de 16, 16 e $18 \%$, respectivamente.

As respostas dos provadores para impressão global indicaram que a moda para os três tratamentos está em torno de 5 (gostei). Destaca-se ainda a ocorrência de pequenas frequências nas categorias "desgostei" e "desgostei muito". Apesar da ocorrência de pequenas frequências em escalas de rejeição, observou-se que as avaliações foram positivas para todos os atributos avaliados no teste sensorial, pois as maiores frequências variaram entre as categorias 5 e 6 .

Os resultados a seguir estão agrupados de acordo com as categorias de resposta mais frequentes, considerando as categorias 5 e 7 como região de aceitação, categoria 4 como região de indiferença e as categorias de 1, 2 e 3 como região de rejeição (Figura 3). 




Figura 3: Histograma de distribuição de frequências para aceitação, indiferença e rejeição para os atributos cor, aroma, sabor e impressão global. $R A$ - região de aceitação; $R I$ - região de indiferença; $R R$ região de rejeição. Tratamento 1: fermento biológico seco, marca Fleischmann $® ;$ Tratamento 2: fermento biológico fresco, marca Levapan ${ }^{\circledR}$ e Tratamento 3: fermento selecionado CA-11, marca LNF Latino Americana Consultoria Assessoria e Importação Ltda.

Todos os tratamentos apresentaram resultados na região de aceitação superiores a $60 \%$ em todos os atributos avaliados. O atributo cor recebeu avaliações superiores a $90 \%$ na região de aceitação nos três tratamentos, destacando-se uma superioridade nos tratamentos 1 e 2.

Para o atributo aroma, o tratamento 2 foi melhor avaliado, totalizando $86 \%$ dos valores hedônicos na região de aceitação. Analisando-se o sabor e a impressão global das bebidas estudadas identificou-se maior aceitação para o tratamento 3 com $72 \%$ e $80 \%$ dos resultados dentro da região de aceitação para os respectivos atributos citados anteriormente.

Dornelles et al. (2009) [17] realizaram teste de aceitação com escala hedônica de nove pontos e avaliaram aroma e impressão global de cachaças obtidas a partir de leveduras, e cachaças produzidas com grânulos de Kefir, e comparando-as com cachaça comercial não envelhecida. As duas amostras de cachaça obtiveram resultados satisfatórios para os atributos avaliados, porém a cachaça produzida a partir de leveduras apresentou maior índice de aceitação comparada com a cachaça produzida com Kefir e a cachaça comercial, por apresentar sabor já conhecido pelos consumidores.

Nascimento e Silva et al. (2019) [18], realizaram análise sensorial de cachaças produzidas em manejo orgânico e convencional, utilizando fermento fresco de levedura S. cerevisiae, concluindo que as amostras de cachaça produzidas com manejo orgânico foram melhor avaliadas independente da variedade de cana utilizada.

Amorim et al. (2016) [1] avaliaram a qualidade físico-química e sensorial de cachaças produzidas com mistura de S. cerevisiae e Meyerozyma caribbica, e concluíram que esse tratamento influenciou na qualidade sensorial, resultando em altas frequências de aceitação, pois promoveu maior produção de compostos voláteis, que potencializam as características de aroma e sabor.

De acordo com as avaliações sensoriais, considerando os índices de aceitação encontrados em outros trabalhos com tratamentos variados, as cachaças produzidas com os três tipos de fermentos de leveduras $S$. cerevisiae, apresentaram elevados índices de aceitação, em todos os atributos descritos, indicando que as práticas de fabricação foram eficazes. 


\section{CONCLUSÃO}

O modelo que melhor se adequou à cinética de degradação das leveduras foi o polinomial de terceira ordem. Pelo menor tempo de degradação dos açúcares, é mais vantajoso utilizar as leveduras comerciais Fleishmann ${ }^{\circledR}$ e Levapan ${ }^{\circledR}$. A acidez volátil foi menor no tratamento com levedura da marca Levapan ${ }^{\circledR}$. Destacam-se como melhor avaliadas pela cor, as cachaças dos tratamentos 1 e 2, para o atributo aroma, as do tratamento 2, e para a característica de sabor e impressão global destacam-se as cachaças do tratamento 3. As cachaças produzidas a partir dos três fermentos apresentaram boas qualidades físico-química e sensorial, demonstrando eficiência no processo fermentativo e síntese de substâncias essenciais para uma boa avaliação do produto.

\section{AGRADECIMENTOS}

Instituto Federal Goiano. Central de Análises Multiusuário Campus Rio Verde. Coordenação de Aperfeiçoamento do Pessoal do Ensino Superior (CAPES).

\section{REFERÊNCIAS BIBLIOGRÁFICAS}

1. Amorim JC, Schwan RF, Duarte WF. Sugar cane spirit (cachaça): Effects of mixed inoculum of yeasts on the sensory and chemical characteristics. Food Res Int. 2016 Jul;85:76-83, doi: 10.1016/j.foodres.2016.04.014.

2. Portugal CB, Silva APD, Bortoletto AM, Alcarde AR. How native yeasts may influence the chemical profile of the Brazilian spirit, cachaça? Food Res Int. 2017 Jan;91:18-25, doi: 10.1016/j.foodres.2016.11.022.

3. Etanislau MLL, Cançado Júnior FL, Paiva BM. Mercado Atual e potencial da cachaça. Informe Agropecuário (EPAMIG). 2002; 23:19-24.

4. Silva MC, Azevedo LC, Carvalho MM, Sá AGB, Lima MS. Elaboração e avaliação da qualidade de aguardentes de frutas submetidas a diferentes tratamentos. Rev Semiárido. 2011 Set;1(2):92-106.

5. Granato D, Oliveira CC, Caruso MSF, Nagato LAF, Alaburda J. Feasibility of diferente chemometric techniques to differentiate comercial Brazilian sugarcane spirits based on chemical markers. Food Res Int. 2014 Jul;60:212-217, doi: 10.1016/j.foodres.2013.09.044.

6. Bortoletto AM, Alcarde AR. Assessment of chemical quality of Brazilian sugar cane spirits and cachaças. Food Control. 2015 Aug;54:1-6, doi: 10.1016/j.foodcont.2015.01.030.

7. Riachi LG, Santos Â, Moreira RFA, De Maria CAB. A review of ethyl carbamate and polycyclic aromatic hydrocarbon contamination risk in cachaça and other Brazilian sugarcane spirits. Food Chem. 2014 Apr;149:159-169, doi: 10.1016/j.foodchem.2013.10.088.

8. Alcarde AR, Monteiro BMS, Belluco AES. Composição química de aguardente de cana-de-açúcar fermentadas por diferentes cepas de leveduras Saccharomyces cerevisiae. Quím Nova. 2012 Jul;35(8):1612-1618, doi: 10.1590/S0100-40422012000800022.

9. Ribeiro MLD, Ferreira OE, Teixeira V, Mutton MA, Mutton JR. Tratamento físico-químico do caldo de cana produz cachaça de qualidade. Rev Ciênc Agron. 2017 Jul;48(3):458-463, doi: 10.5935/18066690.20170053.

10. Silva AP, Silvello GC, Bortoletto AM, Alcarde AR. Composição química de aguardente de cana obtida por diferentes métodos de destilação. Braz J Food Technol. 2020 Fev:23:e2018308, doi: 10.1590/19816723.30818.

11. BRASIL. Ministério da Agricultura, Pecuária e Abastecimento. Instrução Normativa $n^{\circ} 13$ de 29 de junho de 2005: Aprova o Regulamento Técnico para Fixação dos Padrões de Identidade e Qualidade para Aguardente de Cana e para Cachaça. Diário Oficial. Brasília, DF. 30 de junho de 2005. Seção 1, p. 3.

12. Fernandes WJ, Cardoso MG, Vilela FJ, Morais AR, Silva VF, Nelson DL. Physicochemical quality of a blend of domestic cachaças from the south of Minas Gerais. J Food Composition Anal. 2007 May;20:257261, doi: 10.1016/j.jfca.2006.01.012.

13. BRASIL. Ministério da Agricultura, Pecuária e Abastecimento. Instrução Normativa $\mathrm{n}^{\circ} 24$ de 08 de setembro de 2005: Aprova o Manual Operacional de Bebidas e Vinagres. Revoga a Portaria $\mathrm{n}^{\circ} 76$ de 27/11/1986. Diário Oficial. Brasília, DF. 20 de setembro de 2005. Seção 1, p. 11.

14. Borragini MCC, Faria JB. Envelhecimento de cachaça sob circulação forçada e aeração. Alim Nutr. 2010 Jan;21(1):25-30.

15. Bogusz Junior S, Ketzer DCM, Gubert R, Andrades L, Gobo AA. Composição Química da cachaça produzida na região noroeste do Rio Grande do Sul, Brasil. Ciênc Tecnol Aliment. 2006 Out;26(4): 793798, doi: 10.1590/S0101-20612006000400013. 
16. Nikfardjam MP, Maier D. Development of a headspace trap HRGC/MS method for the assessment of the relevance of certain aroma compounds on de sensorial characteristics of commercial apple juice. Food Chem. 2011 Jun; 126(4):1926-1933, doi: 10.1016/j.foodchem.2010.12.021.

17. Dornelles AS, Rodrigues S, Garruti DS. Aceitação e perfil sensorial das cachaças produzidas com Kefir e Saccharomyces cerevisae. Ciênc Tecnol Aliment. 2009 Jul;29(3):518-522, doi: 10.1590/S010120612009000300010.

18. Nascimento e Silva JH, Verruma-Bernardi MR, Margarido LAC, Oliveira AL. Análise sensorial de cachaça produzida em manejo orgânico e convencional. Rev Ciênc Agr. 2019 Mai;42(2):547-556, doi: 10.19084/rca.17426. 